\title{
Concentração e centralização das atividades urbanas: uma perspectiva multiescalar. Reflexões a partir do caso de São Paulo' ${ }^{1}$
}

\author{
Sandra Lencioni ${ }^{2}$
}

\begin{abstract}
RESUMO
A grande dimensão territorial da metrópole contemporânea é produto de um processo que conurba cidades e também fragmenta o território, o que remete à idéia de arquipélago urbano. Essa realidade é analisada a partir da discussão sobre a idéia de aglomeração, já que essa é fundamental para a definição do urbano. Mas, o centro da discussão repousa sobre a necessidade de distinguir dois conceitos para se compreender essa realidade: o de concentração e o de centralização do capital. Enfatiza, também, a necessidade de uma análise multiescalar, pois além da escala topográfica é importante na análise da metrópole contemporânea se considerar a escala topológica, relativa aos fluxos imateriais, pois essa escala insere a questão da distância numa lógica virtual que modifica a noção do longe e do perto, aproximando lugares distantes e distanciando lugares próximos.
\end{abstract}

Palavras chaves: Aglomeração, concentração, centralização, metrópole, escala.

\begin{abstract}
The vast territorial dimension of the contemporary metropolis is a product of the process of conurbanization that also entails the fragmentation of the territory, which leads to the idea of urban archipelago. This reality is analyzed starting from the discussion on the notion of agglomeration, since it is a fundamental notion for the definition of the urban. Yet, the center of the discussion rests on the need of distinguishing between two concepts to understand urban reality: concentration and centralization of the capital. The text emphasizes, also, the need of multi-scalar analysis. Indeed, besides the topographical scale, it is important to consider the topological scales in the analysis of the contemporary metropolis. The topological scale relates to the immaterial flows, putting the issue of distance in a virtual logic that modifies the notions of the far and near, approximating remote places and separating nearby places.
\end{abstract}

Key words: Agglomeration, concentration, centralization, metropolis, scale.

1 Artículo recibido el 5 de octubre de 2007 y aceptado el 24 de febrero de 2008.
Prof. Dr. do Departamento de Geografia da Faculdade de Filosofia, Letras e Ciências Humanas da Universidade de São Paulo (Brasil).

E-mail: slencion@usp.br 
A imagem espraiada e de difícil apreensão dos limites territoriais de São Paulo é testemunho de que essa metrópole é produto de uma urbanização que produziu uma aglomeração difusa que conurba cidades se expandindo por centenas de quilômetros. Por isso, iniciamos nossa discussão colocando em relevo a idéia de aglomeração como elemento importante na definição do urbano. Em seguida, enfatizamos a forma fragmentada da metrópole contemporânea, que metamorfoseou a metrópole compacta típica de grande parte do século XIX e XX. Com características sócio-espaciais historicamente novas, a fragmentação da metrópole contemporânea induz facilmente ao uso da figura de linguagem que nos remete à idéia de que ela se constitui num arquipélago de ilhas urbanas.

O centro da discussão repousa sobre a necessidade de distinguir dois conceitos para se compreender a metrópole contemporânea, o de concentração e o de centralização do capital que consideramos parâmetros indispensáveis para se pensar a dinâmica urbana dos dias atuais. O primeiro, o de concentração do capital, permite entender que embora essa metrópole possa ser representada por imagens que indicam que ela é espraiada e dispersa, é preciso frisar que ela é, igualmente concentrada. Faz parte da racionalidade da acumulação capitalista concentrar um grande número de população, renda, indústrias de alta tecnologia e trabalho qualificado, bem como fazer da metrópole difusa e espraiada territorialmente, uma única bacia de trabalho e habitat, dentre outros aspectos que poderíamos enumerar.

O segundo conceito discutido é o conceito de centralização, que permite esclarecer os mecanismos de administração e controle do capital, que por meio dos serviços voltados às empresas reafirmam e renovam a centralidade da metrópole.

Nas observações finais enfatizamos a necessidade de se considerar, dada a densidade dos fluxos imateriais, a escala topológica que insere a questão da distância numa lógica virtual e de comunicação que modifica a noção do longe e do perto, aproximando lugares distantes e distanciando lugares próximos.

\section{A aglomeração: princípio da construção da cidade e do urbano}

A metrópole espraiada e difusa, como a atual metrópole de São Paulo, indica que estamos sob um patamar da urbanização decorrente de mudanças profundas que alteram a produção do espaço. Compartilhamos da posição de alguns autores, como Lacourt, de que estamos vivendo um processo de metropolização que diz respeito "ao conjunto de processos que privilegiam as grandes dimensões urbanas marcadas pelas transformações do sistema produtivo apreendido a nível internacional e mundial". Esse processo "conduz às organizações e às recomposições territoriais novas, tanto no plano interno dos conjuntos urbanos que lhes dizem respeito, quanto relativos às suas relações externas" (Lacourt, 1999: 64).

Essas organizações e recomposições territoriais novas guardam relação com a cidade e o urbano. Sem entrar no mérito da discussão sobre a relação entre cidade e urbano, que fugiria ao escopo desse trabalho, vamos tecer algumas observações sobre a relação entre aglomeração e cidade, no sentido de indicar que embora a metrópole possa apresentar grande grau de dispersão da mancha urbana, ela é sempre uma aglomeração. Discussão necessária e precedente para podermos compreender que ela é, também, concentração.

A relação entre aglomeração e cidade não é simples e nem é universal, como pode parecer. A primeira observação a ser feita é a de que a aglomeração de homens ou de habitação não produz, necessariamente, uma cidade. Podemos ter aglomerações de homens e de pessoas sem termos cidade e para comprovar essa afirmação basta mencionar as tendas armadas nos desertos ou as feiras itinerantes de escravos da era moderna que embora constituíssem aglomerações não eram cidades.

Um pressuposto fundamental da cidade é a sedentarização, que os exemplos acima não contemplam. Essa observação foi feita por Ratzel e relatada por Derruaux ao enfatizar a sedentarização como um dos pressu- 
postos da cidade (Derruaux, 1964: 561). Porém, apenas esse atributo não basta para considerarmos que as aglomerações sedentárias se constituam cidades. Se assim o fosse consideraríamos muitas aldeias indígenas como sendo cidades.

No caso de relacionarmos a aglomeração, já com seu atributo de ser sedentária, à idéia de cidade, devemos considerar apenas as aglomerações que se caracterizam pelo desenvolvimento de atividades não agrícolas? A resposta a essa questão é negativa, como observou Derriaux, em meados do século $X X$, quando disse que muitas aglomerações constituem cidades muito embora apresentem grande parte de sua população voltada para as atividades agrícolas (Derruaux, 1964). Exemplifica falando de várias aglomerações mediterrâneas, como Mesina, Palermo ou Murcia. Diz ele que essas aglomerações, embora com uma população vinculada ao campo, apresentam aspectos próprios de cidade, tais como o mercado e a administração pública. Esse autor para reforçar a posição de Ratzel, faz um raciocínio em direção oposta dizendo que o fato de um aglomerado se caracterizar por população não agrícola, não significa necessariamente, que estamos diante de uma cidade e dá como exemplo os aglomerados de fábricas com algumas casas ao redor que estão longe de constituírem cidade.

Recuperamos essas premissas da relação entre aglomeração e cidade porque estamos nos referindo à metrópole de São Paulo que se apresenta territorialmente espraiada, com um tecido urbano esgarçado que pode matizar um dos elementos fundamentais de sua constituição que é o de aglomeração. Essa aglomeração pode se apresentar coesa, como o foi no passado, ou dispersa, como tem se apresentado nos dias atuais.

A metrópole contemporânea, devido ao seu espraiamento territorial e a conurbação de cidades apresenta uma densidade populacional menor que a metrópole coesa do passado. Seus limites territoriais são difusos, dado o grande grau de dispersão, por exemplo, da população, das atividades de consumo, da área construída e das atividades produtivas. Mas, essa dispersão não deve comprometer, no entanto, a visão de que ela possui um alto coeficiente de concentração, a exemplo da concentração de trabalho qualificado, de serviços produtivos, ou seja, daqueles serviços voltados ao atendimento às empresas, notadamente de empresas com fortes vínculos com o mercado mundial, de fluxos virtuais, de população, de renda e de edifícios verticalizados.

A cidade de São Paulo, o centro desse aglomerado metropolitano, é a maior praça financeira do país. O número de agências no ano de 2006 era de 2.067, enquanto que o Rio de Janeiro, em segundo lugar, possuía cerca da metade, 1.031 agências. Enquanto as operações de crédito, no Rio de Janeiro, significaram 35 bilhões de reais, em São Paulo esse número foi de 236 bilhões de reais (IBGE, 2006). Quanto aos depósitos totais eles saltaram de 106 bilhões de reais, em 1996, para 204 bilhões em 2001, apresentando um crescimento da ordem de $52 \%$ (Banco Central do Brasil, 2001). Dos 48 maiores bancos do país, 30 deles possuem a sede principal na cidade de São Paulo (Ferreira, 2007: 238). Essa cidade abriga a sede da BOVESPA - Bolsa de Valores de São Paulo-, que se constitui no maior centro de negociação de ações da América Latina concentrando $70 \%$ do volume de negócios realizados (SEMPLA, 2003).

Essa combinação de dispersão e concentração é que configura o espaço da metrópole contemporânea. A metrópole coesa, como "grande cidade", é a forma clássica da metrópole. O seu espraiamento por um extenso território e seus limites imprecisos pode levar a entender que o que é disperso não é o aglomerado, mas o novo patamar da urbanização. Trata-se apenas de uma aparência, pois o que é disperso é a forma que assume a aglomeração. Seja qual for a configuração metropolitana, quer seja um espaço mais denso ou mais disperso, esse espaço é condição, processo e produto associado à urbanização, que tem na idéia de aglomeração um dos elementos centrais de sua definição. Portanto, o que é disperso é sua forma.

Essa gigantesca mancha urbana, como a da atual metrópole de São Paulo, requer incorporação crescente de áreas que chegam ao mercado de terras supervalorizadas em 
relação à valorização anterior. Mas, essas terras apresentarem valor unitário menor em comparação a algumas áreas tradicionais da cidade e é essa dinâmica de preços que faz com que novas áreas sejam continuadamente incorporadas à lógica do mercado de terras da metrópole, contribuindo para a indefinição dos limites metropolitanos.

Uma metrópole espraiada e dispersa significa maior tempo de deslocamento de seu habitantes, maior tráfego de veículos e maior movimento pendular entre o local de moradia e o local de trabalho. Produz-se nessa metrópole uma irracionalidade que cobra do capital maior dispêndio de tempo com a locomoção pela cidade, com possibilidades de se multiplicarem os acidentes de trânsito e de se aumentar o ambiente carregado de poluentes. Tudo isso compromete o funcionamento da metrópole e a própria existência da cidade. Borja e Castells dizem que podemos evoluir "para um mundo sem cidades, ao menos em grande parte do planeta e para a maioria da população. Um mundo organizado em torno de grandes aglomerações difusas de funções econômicas e assentamentos humanos disseminados ao largo de vias de transportes, com zonas semi rurais intersticiais, áreas periurbanas sem controle e serviços desigualmente repartidos em uma infra-estrutura descontínua. O global poderia se organizar em torno de centros de direção, tecnológicos e residenciais das elites, conectados entre si por comunicações a longa distância e redes eletrônicas, enquanto a população poderia individualizar seu habitat na difusão urbana descrita, ou agrupar-se em comunidades defensivas de ideologia quase tribal para assegurar sua sobrevivência em um mundo estruturado globalmente em seu centro e desestruturado localmente em múltiplas periferias" (Borja y Castells, 1997: 13). Advertem, dizendo: "os tons de ciência de ficção de nosso discurso tem a intenção apenas de chamar a atenção do leitor sobre um processo em marcha, inscrito na lógica do potente sistema tecno econômico emergente, mas que de modo algum é uma fatalidade" (Borja y Castells, 1997: 13-14).

No território dessa metrópole espraiada formam-se verdadeiras ilhas urbanas. Tanto quanto um arquipélago em que as ilhas for- mam um conjunto apesar de separadas umas das outras pelo oceano, algumas áreas dessa metrópole constituem verdadeiras ilhas que pouco contato têm com seu entorno, como se tivessem um oceano entre elas. Esse é o caso das áreas de condomínios fechados, que podem apresentar população até maior que a de cidades, onde o que importa não é tanto o contato com o seu entorno, mas o acesso a alguma autopista. Também é o caso dos shopping-centers que se espalham por várias áreas da cidade, bem como das torres de escritório onde se desenvolvem os serviços superiores. Muitas dessas torres são chamadas de edifícios inteligentes porque apresentam infra-estrutura de telecomunicações avançada e otimização dos recursos instados para seu funcionamento, além de segurança e conforto.

Essas ilhas representam a fragmentação da cidade, muito embora essa cidade arquipélago se constitua numa única bacia de habitat e de trabalho. O ir e vir não se dá, preferencialmente, no entorno dessas ilhas, mas no seu interior, a indicar a fragmentação do tecido urbano que é um dos grandes responsáveis pela negação da rua como lugar de encontro de transeuntes e de desiguais. A atmosfera no interior dessas ilhas é mais de um clube do que de uma cidade, não sendo propriamente urbana.

Assim, no interior dessa metrópole espraiada, novas formas de segregação espacial emergem num mosaico onde condomínios de luxo se apresentam ao lado de bairros pobres ou favelas. Esse novo mosaico urbano compromete a tradicional forma de viver na cidade e, do ponto de vista da explicação compromete a interpretação que imperou no final do século XX, o modelo centro-periferia que norteou a compreensão do crescimento urbano das metrópoles latino-americanas.

Assim, a metrópole espraiada, com limites difíceis de precisar, é a expressão máxima da indefinição das fronteiras e da desagregação da cidade compacta típica do início do século XX. Trata-se de uma metrópole difusa, de limites imprecisos, que conurba cidades e se estende por centenas de quilômetros, mas essas características todas não comprometem a interpretação de que 
ela se constitui numa única aglomeração. Reiterando, numa aglomeração que tem hoje a característica de ser dispersa e que só aparentemente pode sugerir contra-senso porque essa forma está de acordo com sua época. Como bem salientou Borja e Castells, a "era das telecomunicações não dilui os centros urbanos, como proclamavam os deterministas tecnológicos, senão, ao contrário, ao permitir a gestão e a comunicação entre si de sistemas urbanos e rurais distantes, tende a concentrar a população em aglomerações territoriais parcialmente descontínuas, de gigantesca dimensão e de características sócio-espaciais historicamente novas..." (Borja y Castells, 1997: 22).

\section{Concentração e centralização: conceitos para pensar a unidade dos processos sócio- espaciais}

A metrópole é antes de qualquer coisa uma aglomeração, particularmente São Paulo é hoje uma aglomeração de grandes extensões territoriais e com limites difíceis de definir. Possui uma dinâmica territorial relacionada à processos sociais que necessita ser compreendida, dada a interação existente entre a dinâmica social e a espacial, que, conforme Massey, só a análise separa, na medida em que não "Há processo espacial sem conteúdo social... O espacial... não existe como um reino separado" (Massey, 1986: 3).

Para melhor compreender essa unidade o recurso a dois conceitos, o de concentração e centralização do capital nos parece fundamental, pois permite relacionar a dinâmica do capital á dinâmica dos lugares. Em particular, possibilita discutirmos a questão da centralidade da cidade no âmago da economia urbana.

Primeiramente, cabe observar que a concentração e a centralização do capital são conceitos relativos à reprodução do capital, referidos, portanto, ao processo social. Em segundo lugar, ressaltar que dizem respeito a movimentos distintos que constituem dois momentos do processo de valorização do capital.
Esses conceitos parecem se confundir, muito embora sejam bastante distintos. Talvez essa confusão tenha origem na própria exposição de O Capital e derive da mudança de nome nas primeiras edições dessa obra. Na primeira e segunda edições de $\mathrm{O}$ Capital, não aparece nenhuma vez o nome centralização. Marx usa os termos concentração adjetivado de simples (concentração simples) para se referir ao que vamos conceituar como concentração e o termo concentração, sem adjetivo, para o que vamos conceituar como centralização. Somente a partir da terceira e quarta edição de O Capital é que aparecem os termos concentração e centralização (Marx, 1984, Livro I, Vol. 3: 778). Essa discussão de Marx está no capítulo de O Capital no qual ele discute a lei geral da acumulação capitalista (Marx, 1984).

Por concentração entende-se o processo que faz expandir os meios de produção e de trabalhadores, ampliando, assim, a base da acumulação e confundindo-se com ela. Por isso, falamos em concentração de capital quando, por exemplo, uma determinada indústria compra mais máquinas para a produção ou quando aumenta o número de trabalhadores. Ou quando um escritório de propaganda e marketing contrata mais publicitários ou mesmo quando equipa o escritório com equipamentos de informática. As implicações desse processo no urbano são de diferentes naturezas, dentre elas, podemos lembrar a concentração das atividades econômicas que modificam, por exemplo, a malha urbana e a aglomeração.

O processo de concentração do capital, por ser um processo de acumulação, está diretamente relacionado à produção da riqueza econômica, a qual tem no indicador de Produto Interno Bruto (PIB) um dos elementos de sua apreensão. Priorizando a perspectiva territorial queremos destacar que a concentração territorial da riqueza gerada no Brasil é bastante nítida.

Examinando-se os 20 municípios que apresentam, para o ano de 2005, maiores PIB do Brasil, 7 estão no Estado de São Paulo perfazendo $18 \%$ do PIB nacional. Só a capital, a cidade de São Paulo, apresenta o índice de $12 \%$, sendo os outros $6 \%$ procedentes dos municípios da região metropoli- 
tana, a saber: Barueri, Guarulhos, São Bernardo do Campo e Osasco, bem como dos municípios de Campinas e São José dos Campos, todos a uma distância menor que 100 quilômetros da cidade de São Paulo (SEADE, 2005).

Os dados do Estado de São Paulo indicam que esse Estado é responsável por $32,3 \%$ do PIB brasileiro ${ }^{3}$. A cidade de São Paulo e mais 4 municípios: Barueri, Guarulhos, São Bernardo do Campo - todos esses pertencentes à Região Metropolitana de São Paulo - e, ainda o município de Campinas, respondem por cerca de $50 \%$ do PIB paulista, $50 \%$ do valor adicionado da indústria paulista e, também por $58 \%$ do valor adicionado dos serviços ${ }^{4}$. Revela-se, assim, a grande concentração territorial da riqueza gerada nesse país de dimensões continentais.
Quanto à centralização, a primeira distinção é que essa não se confunde com a acumulação. Centralizar é, acima de tudo, centralizar capitais. O processo de centralização constitui-se num processo em que frações individuais de capitais se associam, se fundem ou se reagrupam. A centralização é, a rigor, a abolição da autonomia do capital individual; ou seja, significa a expropriação de um capitalista por outro capitalista, que acaba por transformar capitais menores, num capital de maior magnitude. A centralização é, portanto, uma reorganização na distribuição da propriedade dos capitais. Altera-se apenas o agrupamento das partes constitutivas do capital social e, nesse sentido, é que concentra a propriedade do capital, mas não se constitui num processo acumulação, não resultando, portanto, em nenhum aumento do capital social (Marx, 1984, Livro I, Vol. 3: 778). Em outros

Quadro $\mathrm{N}^{\circ} 1$

PRODUTO INTERNO BRUTO DO ESTADO DE SÃO PAULO MUNICÍPIOS COM MAIOR PIB (2005)

\begin{tabular}{|ll|r|r|}
\hline \multirow{2}{*}{ Municípios } & \multicolumn{2}{|c|}{ PIB } \\
\cline { 3 - 4 } & & Em milhões de reais & Porcentagem \\
\hline 1 & São Paulo & 263.177 & 36,2 \\
2 & Barueri & 22.431 & 3,1 \\
3 & Guarulhos & 21.615 & 3,0 \\
4 & Campinas & 20.621 & 2,8 \\
5 & São Bernardo do Campo & 19.448 & 2,7 \\
6 & Osasco & 18.311 & 2,5 \\
7 & São José dos Campos & 17.090 & 2,4 \\
8 & Santo André & 11.427 & 1,6 \\
9 & Jundiaí & 10.185 & 1,4 \\
10 & Ribeirão Preto & 10.096 & 1,4 \\
& Total & 414.401 & 57,1 \\
& Total do Estado de São Paulo & 727.053 & 100,0 \\
\hline
\end{tabular}

Fonte dos dados: SEADE - Fundação Sistema Estadual de Análise de Dados; IBGE - Instituto Brasileiro de Geografia e Estatística (2005).

\footnotetext{
3 Em termos absolutos: 2.248.504 mil reais (IBGE, 2006).

4 Segundo Relatório da empresa de consultoria Pricewaterhouse Coopers, comentado pela Agência
}

Brasil, em artigo de autoria de Alana Gandra, "Ano fecha com aumento de fusões de empresas, mostra pesquisa", no site da Agência Brasil (2006). 
termos, com a centralização do capital desaparecem inúmeros capitais individuais, quer por absorção de uns pelos outros, quer por associações ou fusões entre os capitais, dentre outras formas de centralização.

Nas palavras de Aglietta, enquanto a "concentração simples é, dentro do campo do valor, um fato quantitativo de acumulação desigual que conserva a autonomia dos capitais, a centralização é uma modificação qualitativa que remodela a autonomia dos capitais e cria novas relações de concorrência" (Aglietta, 1986: 195). Acrescenta mais adiante que a "centralização é uma forma violenta de concorrência... É um efeito do processo geral de desvalorização do capital sobre o fracionamento das capitais mediante o qual o movimento da acumulação global encontra novas condições para seu futuro desenvolvimento" (Aglietta, 1986: 196).

A centralização da propriedade do capital coloca sob um mesmo poder, um mesmo comando, o processo que mobiliza e controla os ciclos de valorização dos capitais envolvidos. Esses atributos da propriedade do capital, o de dispor ou por em movimento o capital e o de controlar sua valorização se realiza através da gestão da empresa. Cada vez mais, diante das possibilidades decorrentes da revolução das comunicações e informática, o que é importante não é tanto a proximidade territorial entre as unidades de produção e nem entre a administração dos negócios e a produção industrial, mas a capacidade de controle dos vários e distintos processos de valorização distribuídos em vários lugares, colocando-os sob um mesmo ciclo de movimentação do valor. Exemplificando, o que importa num grupo econômico, numa rede de fornecimento de serviços ou numa rede dispersa de comércio é o controle das unidades dispersas por meio da centralização da gestão empresarial.

Não é novidade nenhuma afirmar que o processo de centralização do capital tem se acentuado, basta ler a imprensa cotidiana para se ter vários exemplos de fusões de empresas, de grupos econômicos comprando outros grupos e de desaparecimento de muitas empresas. As informações econômicas indicam que no ano de 2006 houve 560 transações envolvendo fusões e aquisições de empresas, número $44 \%$ maior que as transações de 2005 (SEADE, 2005). Em 2007, esse número passou a 718, batendo recorde em relação aos anos anteriores. A esse recorde vem se juntar um outro dado importante, os negócios realizados em 2007 foram de maior volume financeiro do que o do ano de 2006 (Pricewaterhouse Coopers, 2008).

Uma outra questão importante é que tem se acentuado o papel de direção e comando da economia exercido pela metrópole de São Paulo, que se constitui num lugar privilegiado de localização das sedes das grandes empresas que atuam no Brasil.

A nosso ver a concentração e a centralização do capital constituem conceitos chaves para se compreender a unidade do processo sócio-espacial e as dinâmicas recentes a partir de um olhar que busca apreender o movimento do capital, muito importante nessa fase de reestruturação econômica sob

Quadro No 2

100 MAIORES EMPRESAS DO BRASIL LOCALIZAÇÃO DAS SEDES (2006)

\begin{tabular}{|l|r|}
\hline Estado de São Paulo & 33 \\
Raidade de São Paulo 100 km a partir da & $\mathbf{2 8}$ \\
cidade de São Paulo & 33 \\
Estado do Rio de Janeiro & 20 \\
Estado de Minas Gerais & 14 \\
Estado da Bahia & 5 \\
Distrito Federal & 4 \\
Estado do Paraná & 5 \\
Estado de Santa Catarina & 4 \\
Estado do Rio Grande do Sul & 3 \\
Demais Estados (19) & 12 \\
Total & 100 \\
\hline
\end{tabular}

Obs.: A localização da sede foi definida segundo a unidade da empresa que responde pelo domicílio fiscal para fins de importo de renda.

Fonte: Fundação Getúlio Vargas (2007). 
o efeito da globalização. Mais do que isso, possibilitam uma interpretação das relações sócio-espaciais situadas além e aquém dos reflexos da globalização.

A principal contribuição do conceito de centralização para a interpretação do urbano é que a gestão empresarial dos grupos econômicos e das grandes empresas em rede priorizam a metrópole e, no caso brasileiro, prioriza a metrópole de São Paulo. É no exercício da função central da metrópole, que é de controle do capital, que se adensam os serviços produtivos, os serviços voltados às empresas, muitas vezes denominados de serviços avançados. Daí provém o grande desenvolvimento dos serviços nas metrópoles e, no caso em exame, da metrópole de São Paulo.

São serviços, portanto, voltados ao consumo produtivo e não individual, tais como os serviços de consultoria jurídica às empresas. Muito embora esses serviços possam ser oferecidos à distância, a proximidade física, muitas vezes, é fundamental, por exemplo, entre advogados, clientes e profissionais especialistas. O contato próximo e imediato entre as pessoas possibilita decisões quanto aos acordos financeiros, às transações internacionais, às aplicações financeiras e aos contratos assinados. Por decorrência, já que esses serviços avançados requerem uma miríade de outros que gravitam em seu redor, aglomeram-se os serviços nas diversas centralidades da metrópole.

Sassen discutindo a produção de serviços produtivos, aqueles voltados à produção, diz que a "característica particular da produção desses serviços, especialmente aqueles envolvidos em operações complexas e inovadoras, é de exprimir sua concentração acentuada nas maiores cidades" (Sassen, 1995: 68).

Nesse sentido, podemos afirmar que o grau de concentração territorial dos serviços produtivos na metrópole tem relação direta com o desempenho de seu papel central. Muitos desses serviços estão diretamente relacionados à gestão do capital, tratando-se de serviços que viabilizam a realização do comando da produção. A nosso ver o que menos importa é saber se a concentração da gestão define a cidade como sendo global ou não. O que nos parece mais relevante e significativo é compreender que há uma relação direta entre o crescimento da centralização do capital nas mais diversas atividades econômicas e o crescimento dos serviços avançados nas metrópoles. Esses, por se acharem concentrados territorialmente garantem a centralidade da metrópole, seu poder de dominação e direção; ou seja, sua hegemonia.

Segundo Smith, enquanto "na cidade pré-capitalista foram as necessidade da troca mercantil que ditaram o movimento de centralização espacial, na cidade capitalista avançada são os ditames financeiros e administrativos que perpetuam a tendência à centralização. Isso ajuda a explicar porque certas atividades chamadas de serviços são centralizadas e outras são suburbanizadas, e porque a reestruturação das áreas centrais assume esta forma corporativa/profissional" (Smith, 2007: 25). Desenvolvendo seu raciocínio podemos dizer que na metrópole moderna, típica de grande parte do século $X X$, a industrialização e as multinacionais foram importantes para o desenvolvimento dos serviços produtivos e, consequentemente, para a centralidade da metrópole. Hoje em dia o que caracteriza a metrópole contemporânea é a presença dos grupos econômicos, notadamente a gestão desses grupos.

É necessário perseguir a idéia de localização dos serviços avançados no interior dos territórios da metrópole (Figura $N^{0} 1$ ). Esses se dão em áreas que expressam o policentrismo, o qual vem progressivamente se desenvolvendo.

E o que é interessante é que essa multicentralidade apresenta uma hierarquia segundo o grau de internacionalização das atividades que nelas se desenvolvem, sendo o topo da pirâmide ocupado pelas áreas onde o grau de internacionalização dos serviços é maior, expresso pela presença de firmas estrangeiras e pelos vínculos densos com o exterior no desenvolvimento dos negócios. Em geral, é nas novas áreas centrais que os hotéis voltados para os homens de negócio apresentam a tendência de nelas se localizarem. Na base da pirâmide temos o centro 
Figura $\mathrm{N}^{\circ} 1$

A EXPANSÃO DAS ATIVIDADES TERCIÁRIAS NA CIDADE DE SÃO PAULO
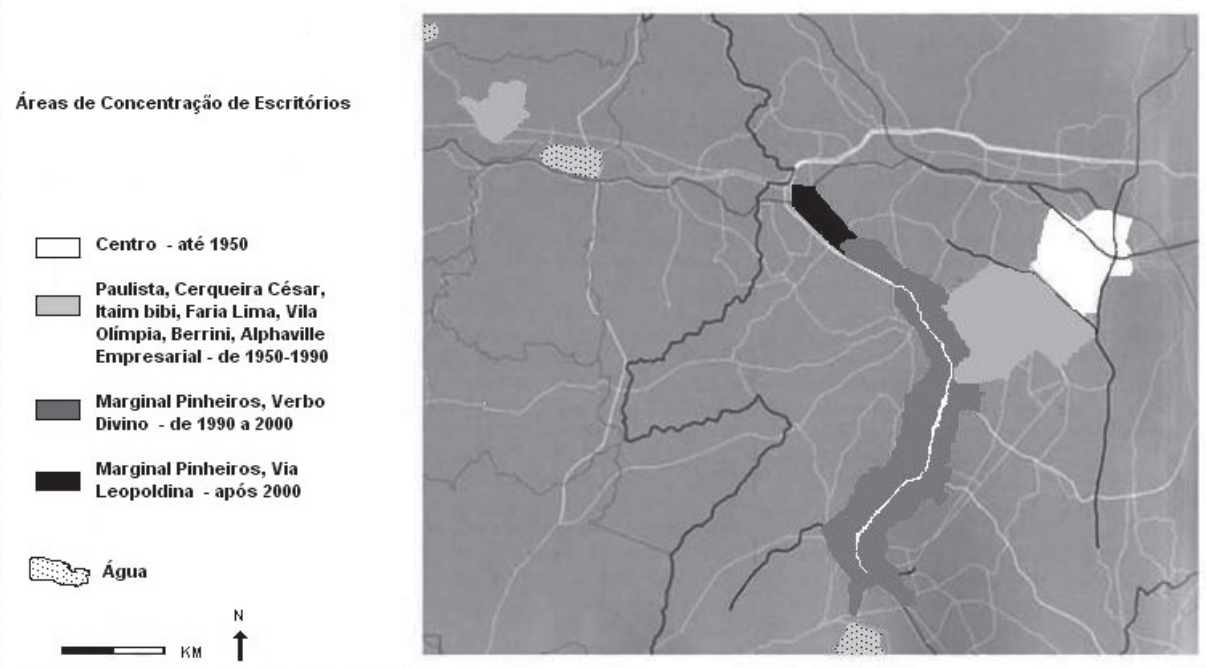

Fonte: Asaptaçao Laboratório de Urbanismo da Metrópole - LUME FAU/USP (2007).

tradicional que embora apresente alguma centralidade e até mesmo fortes laços com o exterior, tem uma característica que o difere das outras áreas centrais da metrópole. Nele e no seu entorno a deterioração de edifícios e o encortiçamento de muitos deles denunciam a degradação da vida urbana e quando há renovação urbana são os planos estratégicos e investimentos estrangeiros que muitas vezes, assumem a cena.

Segundo a importância desses centros na metrópole contemporânea, cujo indicador é a lucratividade dos negócios que aí se desenrolam e o poder de gestão do capital emanado daí, é que podemos perceber a força de uma metrópole. "... Nova lorque, Londres e Tóquio podem ser vista como constituindo um território transnacional de centralidade voltado para um complexo de indústrias e de atividades" (Sassen, 1995: 71). Dizendo de uma outra maneira, cidades globais com Nova lorque, Londres e Tóquio constituem, cada uma delas, um terreno transterritorial de centralidade. O território dessas cidades é global e é essa característica que a distingue das demais metrópoles importantes do mundo.

Além do mais, uma outra característica importante é que na metrópole se adensa a indústria de alta tecnologia e inovadora, num quadro de refluxo da atividade industrial e de não reconversão das áreas tradicionalmente industriais da cidade, que passam a se constituir como resíduos de um outro tempo a espera de reconversão. Desenvolve-se, também, um deslocamento da indústria, em especial dos ramos tradicionais para além da região metropolitana.

A concentração, na metrópole, da indústria de alta tecnologia e da indústria inovadora se deve à necessidade que essas indústrias têm de trabalho qualificado que se faz aí presente, bem como de aproximação com universidades e centros de pesquisa. As empresas voltadas para o mercado externo, bem como das que apresentam maior competitividade e maior agressividade, têm muito a ganhar ao se localizarem na metrópole, dada a densidade de possíveis negócios que a metrópole apresenta, não importando os altos custos dessa localização.

Se de um lado, o da centralidade, a metrópole espraiada apresenta uma hierarquia piramidal relativa às várias centralidades, $\mathrm{O}$ mesmo não pode ser dito em relação às demais áreas da cidade, pois a configuração da metrópole difusa é, como dissemos, de 
um arquipélago, cujo tecido urbano é fragmentado. Apresenta locais em que convivem lado a lado, áreas elitizadas, a exemplo de alguns condomínios fechados, e favelas. Estranhos um ao outro e separados socialmente compartilham uma vizinhança territorial que impossibilita apreendermos arranjos que obedeçam a uma hierarquia piramidal.

Do século XIX ao atual assistimos, assim, a uma trajetória de mutação da metrópole: de compacta para dispersa e de coesa para fragmentada. Desenvolve-se, assim, uma nova lógica espacial que se caracteriza pela dominação do espaço de fluxos sobre a do espaço dos lugares, em que o espaço de fluxos, é "estruturado em circuitos eletrônicos que ligam entre si, globalmente, nodos estratégicos de produção e gestão". E, que se caracteriza, também por se constituir num espaço dos lugares, "como forma territorial de organização da cotidianidade e da experiência de grande parte dos seres humanos" (Borja y Castells, 1997: 67). Para esse autor, "enquanto o espaço de fluxos está globalmente integrado, o espaço dos lugares está localmente fragmentado" (Borja y Castells, 1997: 67). Nesse espaço de fluxos as redes que se estruturam não são mais redes hierarquizadas, como no passado, sendo, sobretudo, redes anastomosadas.

Podemos, esquematicamente, apresentar algumas características mencionadas nesse texto relacionadas à metrópole que se desenvolveu do último terço do século XIX ao último terço do século $X X$; ou seja, da metrópole moderna e da metrópole contemporânea, como São Paulo, que anuncia uma nova forma de viver na cidade (Quadro $\mathrm{N}^{\circ}$ 1). Não é demais advertir que todo esquema é simplificador, mas tem o mérito de fazer saltar à vista transformações que consideramos relevantes para a discussão em pauta.

A metrópole contemporânea é uma realidade nova que necessita ser compreendida de várias perspectivas. Aqui, a ênfase foi dada aos processos de concentração e de centralização como emuladores de novas visões sobre a metropolização contemporânea.

Situados enquanto processos do capital, a concentração do capital se relaciona à aglomeração urbana e sua contra face, à dispersão. Por outro lado, a centralização do

Quadro $N^{\circ} 3$

ALGUMAS CARACTERÍSTICAS DA METRÓPOLE MODERNA E DA METRÓPOLE CONTEMPORÂNEA

\begin{tabular}{|l|l|l|}
\hline & \multicolumn{1}{|c|}{ Metrópole Moderna } & \multicolumn{1}{|c|}{ Metrópole Contemporânea } \\
\hline Processo & Urbanização & Metropolização \\
Aglomeração & Concentrada & Dispersa \\
Espaço & Espaço dos lugares/espaço & Espaço dos fluxos/espaço dos \\
& dos fluxos & Metrópole difusa \\
Extensão territorial & Metrópole coesa & Densidade em declínio \\
População/superfície & Alta densidade & Fragmentada \\
Forma & Contínua & Percurso sem integração \\
Mobilidade & Integração no percurso & Crescimento mais linear \\
Desenho & Crescimento radiocêntrico & Indefinidos \\
Limites & Definidos & Intensificação do policentrismo \\
Centralidade & Policêntrica & Planos estratégicos \\
Renovação urbana & Planos de recuperação & Anastomosadas \\
Redes & Hierárquicas & Gestão \\
Capital & Produção & \\
\hline
\end{tabular}

Fonte: Elaboração própia. 
capital se vincula estreitamente à questão da centralidade urbana. A aglomeração, que discutimos na primeira parte desse texto e a concentração, dispersão e centralidade constituem processos espaciais importantes para se compreender a dinâmica da metrópole contemporânea. Uma metrópole, como dissemos, onde predomina o espaço de fluxos sobre o espaço dos lugares. Nessa dialética reside uma outra questão relacionada à necessidade de se incorporar uma visão multiescalar na análise para que se possa apreender dimensões novas da lógica espacial na sua importância devida.

\section{Considerações finais}

Imperioso é considerarmos os fluxos materiais e imateriais que se desenvolvem no espaço. Daí a necessidade de transcendermos à escala que leva em conta a dimensão da superfície do terreno e incorporar na análise a dimensão da escala que toma em consideração os fluxos imateriais. A justificativa é a de que a dinâmica dos processos espaciais não repousa apenas sob a lógica topográfica, mas também sob a lógica topológica.

A lógica topográfica está relacionada à distância entre dois lugares e tem como referência a rede de infra-estrutura de circulação. A distância corresponde a um intervalo de espaço e de tempo entre dois lugares e dois instantes, medido em termos de superfície e de tempo de percurso. Exemplificando, a distância entre $\mathrm{A}$ e $\mathrm{B}$ é de 5 quilômetros e de 10 minutos. A lógica topológica, por outro lado, insere a distância numa lógica virtual possibilitada pela revolução da informática e comunicações. Nesse caso, a distância entre A e B é medida apenas em intervalo de tempo dos fluxos imateriais e, no seu limite, pode chegar à instantaneidade, anulando-se o intervalo e, conseqüentemente, a própria distância.

Sob essas duas lógicas, ou seja, a partir de um espectro multiescalar, é que a aglomeração e a dispersão metropolitana, enquanto processos espaciais devem ser examinadas na análise da metrópole contemporânea. Pela lógica topográfica, relativa à superfície do terreno, podemos ver a densidade dos lugares, quer em termos de edificações e de atividades urbanas, concorrendo para distinguirmos a concentração da dispersão. Pela lógica topológica apreendemos a densidade virtual dos lugares, medida em termos dos fluxos imateriais entre dois pontos, que dizem respeito aos fluxos de informação e comunicação.

Muito embora não haja indicadores sistematizados para dimensionar a densidade virtual dos lugares, o que mostra que as necessidades da pesquisa vão além das possibilidades disponíveis, alguns dados indiretos, levando-se em conta apenas os dados relativos à informação, podem ser indicativos da densidade virtual dos lugares. Por exemplo, o número de empresas de telecomunicações, em 2007 que atuam em São Paulo é de 389. Se compararmos com a cidade que se apresenta em segundo lugar, o Rio de Janeiro, com o dado de 141 empresas de telecomunicações, podemos verificar que São Paulo tem 2,7 vezes mais empresas que o Rio de Janeiro. Um outro dado relativo ao número de provedores de Internet aponta para São Paulo o número de 172 provedores de Internet e para o Rio de Janeiro, o de 28 (OESP, 2007).

Significativo é também, o número de domínios ".com.br" e ".org.br" da cidade de São Paulo. Esses domínios representam 90\% do total de domínios existentes no Brasil (Gusmão e Ramos, 2006: 136). Os dados de 2003 indicam que a cidade de São Paulo tinha 49\% desses domínios do Brasil, enquanto que a participação da cidade do Rio de Janeiro, a segunda colocada é cinco vezes menor. Tendo como referência o Estado de São Paulo, a cidade de São Paulo detém 58\% desses domínios (Gusmão e Ramos, 2006: 137).

A visão multiescalar permite, assim, superar a perspectiva apenas topográfica, nos libertando de uma visão de uma única natureza, de um único referente. Porque há possibilidades de se examinar um fenômeno por meio de várias escalas diferentes é importante ir além da perspectiva topográfica. Podemos, cabe acrescentar, examinar um fenômeno apenas da perspectiva topográfica, utilizando-se várias escalas e esse procedimento não deixa de ter, também, uma perspectiva multiescalar. No entanto, se está considerando apenas um referente - o topo- 
gráfico -, que compromete uma visão mais ampla dos fenômenos espaciais. É necessário ir além.

Buscando maior clareza, vejamos o exemplo: se tomarmos apenas a escala na perspectiva topográfica, a opção por diferentes escalas, 1: 25.000 ou 1: 100.000, levará à interpretação de que o fenômeno urbano é disperso, no primeiro caso e, concentrado, no segundo, o que resvala, facilmente, num inadequado relativismo. $\mathrm{O}$ mesmo pode ser dito quando nessa mesma perspectiva e a partir de uma grande escala se interpreta que os bairros elitizados estão mesclados com os bairros empobrecidos. Mas, se examinados a partir de numa pequena escala a conclusão é a de que não se trata de uma mescla, mas, ao contrário, de uma separação. É por isso que Harvey alerta que o que é relevante ou faz sentido numa escala não o é em outra (Harvey, 2004: 108).

Importa, ainda, destacar a importância da escala do corpo humano no espaço urbano, relativa ao lugar que o corpo individual ocupa na cidade. Essa dimensão é topográfica mas parece muito ausente na discussão sobre a cidade. Conforme Harvey, o "capital se empenha continuadamente em moldar os corpos de acordo com seus próprios requisitos, ao mesmo tempo em que internaliza em seu modus operandi efeitos de desejos corporais, vontades, necessidades e relações sociais..." (Harvey, 2004: 157).

Isso significa que além de moldar a experiência individual dos corpos, o capital busca socialmente discipliná-los na produção e, o que é importante para a discussão em pauta, discipliná-los, também, na cidade. O que vem ocorrendo em Los Angeles é um exemplo do esforço em disciplinar o corpo humano na cidade. Foi aprovada recentemente a norma, pelo City Council, de que os moradores de rua podem dormir nas calçadas no período compreendido entre 9 horas da noite às 6 da manhã do dia seguinte se eles guardarem, pelo ao menos, 3 metros das casas ou das lojas (International Herald Tribune, 2007).

Numa perspectiva multiescalar, como a discutida nesse texto, que envolve escalas de natureza diferentes, a pouca distância em termos topográficos pode ser uma grande distância em termos virtuais; ou seja, a pouca distância em termos topográficos entre A e B, por exemplo, 5 quilômetros, pode ser uma grande distância em termos virtuais se A não tiver uma infra-estrutura de informação e comunicação que possa se comunicar com B, restando, assim, muito distante de B. Por outro lado, a longa distância, medida em quilômetros de superfície, pode, na escala topológica, ser praticamente anulada dada a capacidade dos fluxos imateriais.

Pumain interroga se as novas tecnologias de informação e de comunicação não estariam conduzindo a uma geografia sem escala (Pumain, 2003: 1). E, Buzenot diz que daqui em diante, as interações espaciais não se farão mais unicamente segundo as regras de um espaço topográfico onde as distancias são os fatores de diferenciação, mas segundo as regras de um espaço topológico onde a capacidade de estar conectado ou vinculado torna-se fator de diferenciação e gerador de desigualdades" (Buzenot, 2007).

Devemos considerar, também, uma característica dos dias atuais decorrente do desenvolvimento do território em rede que veio suplantar o território de redes. Para Mogin "o território rede se caracteriza essencialmente... por ter propriedades de ordem 'topológica' que valorizam as 'relações horizontais' e sua ligação pólo a pólo a expensas das relações verticais e piramidais, pólohinterlância". Acrescenta, ainda, que a "cidade global está presa em uma rede (web) que corresponde a uma organização em rede (reticulum), isto é, a uma estruturação que privilegia a horizontalidade e cria hierarquias que não são de natureza piramidal" (Mogin, 2006: 226).

A idéia de ordem topológica vem reafirmar a importância de se considerar os fluxos imateriais na análise espacial, como observamos anteriormente, já que a virtualidade subverteu a maneira de se pensar o espaço. Dizendo de uma outra maneira, o virtual reafirmou a importância de se levar em conta as relações horizontais, por exemplo, as relações entre cidades globais, e, também as relações verticais como as do global em relação ao local, sem necessariamente passar pelo regional ou nacional. 
O que é importante assinalar é que a perspectiva multiescalar ao permitir levar em conta as naturezas diferentes de escala possibilita conciliar tanto a escala topográfica como a escala topológica, fazendo justapor a distância e a proximidade em termos de extensão territorial e em termos virtuais. Um material, outro imaterial, mas ambos reais e concretos porque se constituem, como nos ensina a dialética, em sínteses de múltiplas determinações, dentre elas, a da história na totalidade social concreta. Por isso, a questão da escala topológica só emerge quando se realiza a possibilidade de uma sociedade estruturada não só em termos de fluxos materiais, mas, também, imateriais. Dizendo de uma outra forma, uma visão apenas topográfica, ou seja, que leve em conta apenas a escala da superfície do terreno, pode perder a dimensão de que a forma territorial dispersa da metrópole contemporânea contém alta concentração de vínculos virtuais que aproximam os lugares.

Em síntese, o que se buscou assinalar nesse texto é que a metrópole contemporânea, como a metrópole de São Paulo, combina em vários níveis e dimensões, uma rede de fluxos materiais e imateriais que a análise multiescalar deve apreender por meio de uma análise multiescalar. Particularmente no caso da escala lógica, é importante perceber, mesmo de forma estimativa e aproximada, a rede de fluxos imateriais que permite dimensionar as redes de relações que emanam da metrópole. Além desse aspecto, buscou revelar que na metrópole contemporânea se realizam movimentos de concentração e de centralização sócio-espaciais (do capital e territorial), nos quais a concentração tende a relacionar com o homogêneo e o repetitivo, enquanto que à centralização ao disperso e heterogêneo.

\section{Referências bibliográficas}

ALANA GANDRA. Ano fecha com aumento de fusões de empresas, mostra pesquisa. Rio de Janeiro: Agencia Brasil, 2006. Disponível em Internet:

www.agenciabrasil.gov.br/noticias/2006/12/ 27/materia.2006-12-27.0416017870/view

AGLIETTA, M. Regulación y crisis del capitalismo. La experiencia de los Estados

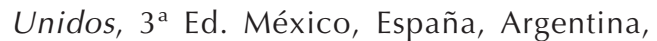
Colombia: Siglo Veintiuno Editores, 1986.

BANCO CENTRAL DO BRASIL. Bacen/ Departamento Econômico. Brasil: Fundação SEADE, 2001.

BORJA, J. y CASTELLS, M. Local y global. La gestión de las ciudades en la era de la información. Madrid: Santillana S. A. -Taurus, 1997.

BUZENOT, L. Demarche du géographie et raisonnement multiscalaire. Hisgeo, 2007. Disponível em Internet: http://histgeo.ac-aixmarseille.fr/a/div/d043.htm.

DERRUAUX, M. Tratado de geografia humana. Barcelona: Editorial Vicens-Vives, 1964.

FERREIRA, J. S. W. O mito da cidade-global. O papel da ideologia na produção do espaço urbano. São Paulo: Ed. Vozes, 2007.

FUNDAÇAO GETÚLIO VARGAS. 100 maiores empresas do brasil localização das sedes (2006). Conjuntura Econômica, 2007.

GUSMÃO, R. e RAMOS, M. Concentração regional da C\&T no Brasil - perfil da liderança paulista no cenário nacional. São Paulo em Perspectiva, 2006, Vol. 20, № 3, p.120-141. Disponível em Internet: www.seade.gov.br/produtos/spp/v20n03/ v20n03_10.pdf.

HARVEY, D. Espaços da esperança. São Paulo: Ed. Loyola, 2004.

IBGE (Instituto Brasileiro de Geografia e Estatística). Producto Interno Bruto dos $\mathrm{Mu}$ nicípios. Brasil: IBGE, 2006.

INTERNATIONAL HERALD TRIBUNE. Los Angeles. Homeless allowed to sleep on sidewalks. International Herald Tribune, 2007, 12 out., p. 6.

LACOURT, C. L. Méthodologie de recherche et théorisation des villes. In: LACOUR, C. et PUISSANT, S. (Eds.). La Métropolisation. Croissance, Diversité, Fractures. Paris: Ed. Anthropos, 1999, p. 63-113.

LABORATÓRIO DE URBANISMO DA METRÓPOLE (LUME). Mapa Áreas de con- 
centração de Escritórios. Sao Paulo: FAU/ USP, 2007.

MARX, K. El capital. Critica de la economia política. México, España, Argentina, Colombia: Siglo Veintiuno Ed., 1984, Capítulo XXIII, Livro I, Vol. 3, p. 759-890.

MASSEY, D. Geography matters, $2^{\mathrm{a}}$ ed. Cambridge: Cambridge University Press, 1986.

MOGIN, O. La condición urbana. La ciudad a la hora de la mundialización. Buenos Aires, Barcelona, México: Paidós, 2006.

OESP. Provedores de internet e para São Paulo. São Paulo: OESP, O Estado de São Paulo, 2007. Disponível em Internet: www.estado.com.br

PRICEWATERHOUSECOOPERS, Segundo Relatório da empresa de consultoria PricewaterhouseCoopers. Folha On-Line, 2008. Disponível em Internet:

www1.folha.uol.com.br/folha/dinheiro/ ult91u364580.shtm.
PUMAIN, D. Du local au global, une géographie sans échelles. Cybergéo, 2003. Disponível em Internet: www.cybergeo.eu.index594.html.

SEADE (Fundação Sistema Estadual de Análise de Dados). O PIB dos Municípios Paulistas em 2005. São Paulo: SEADE, 2005. Disponível em Internet:

www.seade.gov.br/produtos/pibmun/pdfs/ PIBNunicpal_2005.pdf

SEMPLA - Secretaria Municipal de Planejamento de São Paulo. Informe. Sao Paulo: SEMPLA, 2003.

SASSEN, S. On concentration and centrality in the global city. In: KNOX, P. and TAYLOR, P. J. World cities in a world system. Cambridge: Cambridge University Press, 1995, p. 63-75.

SMITH, N. Gentrificação, a fronteira e a reestruturação do espaço urbano. GEOUSP, 2007, No 21, p. 15-29. 